\title{
Design of Industrial Floors-Review of Guidelines, Special Designing Issues (Part 1)
}

\author{
Peter Karoly Juhasz ${ }^{1}$ and Peter Schaul ${ }^{2}$ \\ 1. Czako Adolf Laboratory of Department of Mechanics, Materials \& Structures, Budapest University of Technology and Economics, \\ Kiskunfelegyhaza 6100, Hungary \\ 2. Department of Construction Materials and Technologies, Budapest University of Technology and Economics, Budapest 1135, \\ Hungary
}

\begin{abstract}
We are placing more and more emphasis on the design of industrial floors when designing the structure of buildings. Currently there are only a few approved designing guidelines that practicing engineers can use to easily design industrial floors. Rather the best practice is that the manufacturers of certain products (concrete fibre reinforcement, dilatation joints) carry out the more or less professional designing. In addition, there are numerous incurring questions in connection with applying the internationally approved guidelines in terms of applicability and reliability. Our paper is based on years of experience in designing industrial floors. In the first part the main guidelines, their characteristics and opportunities of application are discussed. In the second part we take a closer look at the most common TR34 British guideline, presenting its most significant designing formulas, which support engineering practitioners in carrying out the design of industrial floors on their own. In the third part we demonstrate advanced finite element analyses, comparing results with real sized experiments and with results of the guidelines.
\end{abstract}

Key words: Industrial floors, special design, TR34, ACI360.

\section{Introduction}

The calculation of industrial floors was always a black sheep when designing industrial buildings, so designers gladly assigned this task to constructors, mostly due to the lack of an utilizable technical guideline. Professional construction companies produce industrial floors relying on several decades of experience, on their own beliefs, and on various technologies and used materials. Some construction companies prefer reinforced concrete industrial floor, some believe in fibre reinforced concrete while other construction companies consider the well-designed concrete technology instead of any type of reinforcement. With the appearance of fibre reinforced concrete manufacturers gladly take over the design of industrial floors, where most of the times the price of the applied floor is decisive, instead of its quality.

Corresponding author: Peter Karoly Juhasz, Ph.D., research field: FRC.
Rarely can the general designer have a say or wants to have a say at all, the issue of responsibility is unclear. The main reason for this shortcoming is that the designers do not have a standard with which they could design industrial floors.

\section{Designing Methods and Guidelines}

When designing industrial floors, the following designing methods can be mentioned:

- manual designing;

- linear finite element analysis;

- non-linear finite element analysis.

Most of the guidelines recommend various formulas for manual designing, they mention the finite element analysis at best, but do not make recommendations to its application [1-4].

\section{$2.1 T R 34$}

The most widely known and approved designing guideline for industrial floors in Europe is the TR34 
technical guideline (Technical report 34-Concrete Industrial Ground Floors-A Guide to Design and Construction) made by the British the Concrete Society [3]. It is already at its fourth publication today, the editions were published in 1988, 1994, 2003 and 2013. The third edition was suitable to design plain concrete floors or fibre reinforced concrete floors, while the fourth edition was adequate for designing most types of the industrial floors, in terms of materials it involved plain concrete, reinforced concrete, textile reinforced concrete, fibre reinforced concrete and hybrid, also known as fibre and traditional steel mesh reinforced concrete.

All the editions typically define the subgrade support from the modulus of subgrade reaction $(k)$, however the modulus of subgrade reaction can be calculated from the soil value of $C B R$ (California bearing ratio) or from the elastic modulus $\left(E_{\mathrm{v} 2}\right)$.

In case such data are not available modulus of subgrade reaction has to be taken with a minimum value, which value has to be verified in situ before initiating the construction. TR34 specifies limitations to the thickness of the industrial floor; the minimal thickness is $100 \mathrm{~mm}$ according to the third edition, while the fourth edition specifies a $150 \mathrm{~mm}$ value.

The design parameters for the concrete are according to EUROCODE [5]. A significant issue is the consideration of fibre reinforcement upon designing, which issue presents a relevant difference between the 2003 and 2013 editions. While the third edition uses the $R_{\mathrm{e} 3}$ value for characterizing fibre reinforced concretes, then the fourth edition tended to use solely the more precise CMOD (Crack Mouth Opening Displacement) values of residual flexural tension strength. Defining the values of $R_{\mathrm{e} 3}$ and residual flexural tension strength is the task of the manufacturer or distributor of the fibre in each case, however calculating values of residual flexural tension strength at defined CMOD values is more complex, so by the release of the fourth edition manufacturers/distributors had to face a more challenging task. Although by these values of residual flexural tension strength the fibre reinforced concrete industrial floor can be designed much more precisely. It is also important to mention that the third edition provided a minimum $R_{\mathrm{e} 3}$ value which the performance of the fibre had to reach, without which the industrial floor could only be designed as plain concrete.

Load bearing capacity of industrial floors should be designed to take positive and negative moment and shear in both editions. Positive moment causes cracks on the lower surface of the industrial floor while negative moment on its upper surface. According to the TR34, load bearing capacity of the industrial floor lasts until the first crack on the upper surface appears, which in reality is not true, as the first crack cannot be seen by the naked eye, and by conforming to the requirements of the serviceability limit state (maximum crack width) an even greater load bearing capacity can be considered. Based on these TR34 is regarded as conservative from the aspect of defining load bearing capacity. There are differences between the two editions from the aspect of shear resistance as well. The third edition allows the consideration of shear resistance of fibre reinforcement solely for steel fibre reinforcement, as opposed to the fourth edition where even steel fibre reinforcement can be considered for shear solely together with traditional reinforcement. So fibre reinforcement cannot be considered from the aspect of shear that needs to be designed as plain concrete.

The 2003 edition defines safety factors at materials and at loads too. Safety factors at loads are broad and not too differentiated. The 2013 edition contains even more differentiated safety factors in terms of point loads, however, the principle of divided safety does not prevail at line loads and uniformly distributed loads, because the safety factor is only considered at material. Based on the TR34 several loads can be designed, which can be point load, two close point loads, two point loads, four point loads (e.g., legs of a shelf), line load or even distributed load. Calculations 
can be made on the internal field, at saw-cut joints, construction joints and on free edge in case of point loads. The impact of the possibly connecting reinforcement and dowels can be considered upon dilatations. The opportunity of designing for shrinkage appeared in the edition of 2003, which considers the effects of thermal expansion loads deriving from shrinkage and thermal difference. The 2013 edition no longer featured the design for shrinkage, as according to the edition, if the conditions of proper concrete technology, construction and formation of dilatation are fulfilled, this issue is non-relevant. In the edition of 2013 design for fatigue was released as a novelty, which was carried out as loads of forklifts, at the same time, it provided a formula solely for the fabric reinforced concrete industrial floors.

To sum it up, most types of industrial floors can be designed by the 2013 edition of TR 34 and by adopting certain parts of the 2003 edition (e.g., design for shrinkage).

\subsection{ACI 360}

The correspondent of TR34 is the ACI360 guideline [1] issued by the American Concrete Institute in the USA.

The guidelines provide a detailed description for construction of industrial floors, methods of forming dilatations and for application of the necessary dilatation joints. The guideline differentiates between plain concrete floors and floors of various reinforcement. The guideline considers steel bar, steeland synthetic macro fibre as reinforcement. The guideline declares that synthetic micro fibres do not cause additional load bearing capacity to floors, moreover, they are not suitable for limiting shrinkage cracks deriving from drying shrinkage. The guideline details the methods of determining geotechnical features as well as the soil parameters necessary for the proper functionality of the floor. The guideline provides what the compactness of the various types of soils can range between in a table form. Soil dilatations are divided into three groups by the guideline which provides a detailed description of its constructions and required dilatation joints. These are namely the cut dilatation, full isolation and joined/joint dilatation. Loads occurring on the floors appear in the detailed description, where the possible occurring impacts of the structure are also mentioned. Safety factors carry a greater value than those of the European standards, the value of this range between 1.7 and 2.0 depending on the type of load.

As a background to the calculations the guideline mentions that determination of peak load of the plate supported by springs is carried out based on the yield line theory and that it considers the Winkler-type foundations at the plate supported by springs, but does not demonstrate details of the calculation. Upon defining the peak load which occurs as the effect of point load the guideline demonstrates the various formulas depending on the location of the point load (free corner, free edge, internal), however it does not provide a recommendation for two and four point loads located at a certain distance from each other. It is to be noted that the guideline uses similar formulas to TR34 for defining the peak load, although it uses strong approximations various places, as $2 \pi=6$.

The guideline demonstrates the calculation of fibre reinforced concrete floors by a separate example. It considers the effect of fibre reinforcement based on the coefficient of $R_{\mathrm{e} 3}$ formerly ceased in Europe. This measure is the quotient of the average value of the peak load of concrete and fibre reinforcement added residual flexural tension strength.

\subsection{Austrian Guideline}

The Austrian guideline, similarly to the TR34 and ACI360 guidelines, was published by the Austrian concrete society (Österreichische Vereinigung für Beton-und Bautechnik), titled Merkblatt-Herstellung von faserbewehrten monolithischen Betonplatten, which was built entirely on the basis of the TR34 for fibre reinforced concrete industrial floors. Several 
approaches which were mentioned by the ACI360 can be found in the Austrian guideline.

\subsection{The Book of Lohmeyer-Ebeling}

Numerous professional books were published on the design of industrial floors besides the already mentioned ones. One of the most widely known is the book written by Lohmeyer-Ebeling: Concrete Industrial Floors for Manufacturing and Warehouses (Betonböden für Produktions-und Lagerhallen) [4]. The book establishes its own safety factors and designing methods by an individual interpretation of industrial floors for the designing of the occurring loads and effects, including the shrinkage and hump of the concrete floor. There are plenty of rather useful parameters in the book, which can even be applied for complex finite element analysis. The book demonstrates the particular environmental classes in detail, as well as the types of concrete recommended to use in this environment. Moreover, it provides recommendations to factors that are quite beneficial in practice (friction coefficients, soil data).

The book takes the designing steps into account, including the concrete mix designs, and recites the general and special requirements raised towards industrial floors. It not only makes detailed recommendations for the development of floor dilatations, the placement of the necessary reinforcement, but also discusses repairing and examining faulty floors. The book offers practical advice on the development of certain structural elements (cut dilatation, surfacing, subgrade comprising) besides theoretical presentation.

\section{Special Issues in Designing}

\subsection{Safety Factors}

The design of industrial floors is a special design task, which requires a different approach, from defining loads to the method of designing than a traditional structural element. Thus Lohmeyer and
Ebeling consider that industrial floors do not belong to the category of structural elements, stating that "industrial concrete floors do not collapse in case of failure, thus will not be dangerous for building stability or people's life", so safety factors of EUROCODE do not apply to it. Lohmeyer and Ebeling use its own safety factors, which depend on numerous factors, from the method of usage through the requirements to the quality of construction.

Such differences can be found at various points of TR34 where $\gamma=1.50$ provided by EUROCODE at the safety factors of the racking leg was decreased to 1.20 , saying that loads of the racking legs are controlled. Let us take a look at an example: there is a racking leg with the ability of taking a maximum $50 \mathrm{kN}$. So the question arises that when the racking leg is overloaded, will it break sooner than to overload the industrial floor? However, this train of thought is flawed, as the safety factor was also considered with one racking leg, and it is probably capable of taking a greater load. Ignoring overload at a racking leg is a faulty supposition based on our opinion (unlike a full water tank, where in case of overload, water runs out of the tank, thus pressure cannot be physically larger). The other discrepancy from the principles of EUROCODE is at the partial safety factor method, where by considering surface loads TR34 states that safety factors of loads do not need to be utilized, as these have been already taken into consideration at the flexural-tension strength of concrete. This is exactly the essence of the partial safety factor method, where a safety factor is taken in case of loads, as well as at the material. Moreover, further safety factors occur at defining the structural model.

Modifying safety factors like this might seem logical, however there is no reference or concession in EUROCODE about it. This decreasing of the safety factor is similarly questionable for up-to-date, high-demand industrial floors, although it does impose a risk on human lives, still, the degree of financial damages can be significant. Based on the above, the 
engineer should contemplate safety factors on his own, during which individual demand of the client, quality of the floor and construction conditions should all be taken into consideration. Applied safety factors should be fixed in calculation and accepted by the client.

\subsection{Types and Determination of the Loads}

Maximum live load on the surface of slabs needs to be defined during the designing of slabs, where the structure needs to be designed to design value increased by the safety factor in the ultimate limit state, and for characteristic value in the serviceability limit state. Accordingly, load bearing capacity of slabs is defined by a value of $\mathrm{kN} / \mathrm{m}^{2}$. Clients prefer defining this value for industrial floors as well, but in this case the value does not reveal much about the actual load arising upon utilization of the floor. Moreover, surface load occurring on the whole surface of a floor supported on its whole surface barely causes bending movement of the floor (the floor can subside, and a vertical normal stress arises in it, which is smaller by a magnitude than the compressive strength of concrete). Bending moment occurs in the floor if these loads affect the floor discontinuously. There is a load state where negative and positive moment takes maximum value. However, neither of the guidelines states whether this load state can exist in reality, or how the construction and saw-cut joints can modify it. Usually a further problem when defining surface loads upon providing loads of the floor is exaggerating values of the loads. A loading of $100 \mathrm{kN} / \mathrm{m}^{2}$ can rarely occur in reality, it is hard to imagine that loads of this size are stored lying on the surface of the floor, it is rather typical to store them on shelves or in containers. These containers have legs which transmit point loads to the industrial floor. Upon defining characteristic load during designing it is worth beginning with materials to-be-placed or to-be-stored on the floor (on shelves, in containers), from machines working on the floor and vehicles moving on the floor (forklifts and trucks), than from a value provided by surface load. If function of the floor is not yet known, then maximum values can be defined, which later requires adjustment.

\subsection{Design to Shrinkage, Distance of Construction and Saw-Cut Joints}

Designing of concrete structures to shrinkage is a rather complex task. On one hand concrete needs to be modelled by a variable material model, while the loads affecting it are constantly changing. The degree of shrinkage is defined by numerous factors: concrete $\operatorname{mix}(w / c$ ratio, fine part and type of the cement), weather during construction (temperature, humidity), method of construction, content and quality of curing. Practically these factors cannot be considered in the calculation, though there is a method for calculating their estimated value in the standards. Their design would be important, as one of the main reasons for cracking of industrial floors is the shrinkage of concrete. Saw-cut joints are made to prevent this cracking, which joints should be made at an early age of the concrete, thus controlling the appearance of the developing cracks (localization of the cracks). Only Lohmeyer-Ebeling offers a method for designing the distance of construction and saw-cut joints, which takes the hardened concrete into consideration.

The industry is ahead of the standards and guidelines in this respect too, as the main current tendency is the construction of the jointless (or with a little exaggeration jointless) industrial floors. There are several directions offering a solution for this. The most obvious is the reinforced industrial floor amended by fibre reinforcement occasionally. The same result can be achieved by a high dosage of steel fibres, for which Dramix provides methods of designing and construction. Dramix mentions the significance of concrete technology, proper compaction and curing in its designing solution. The point of the designing process is the calculating stress distribution inside the cross section, where material parameters of young concrete and fully hardened 
concrete are considered. Designing is carried out to the limitation of the crack width, so compliance with the SLS (serviceability limit state) is a requirement; designing for the USL (ultimate limit state) is managed separately. Fibre reinforcement is applied together with traditional reinforcement in the designing process, but the calculation method does not consider distance of the construction and saw-cut joints, which would be of key importance in case of jointless industrial floors.

Dramix places special emphasis on the construction of jointless industrial floors as well. It covers the issue of subgrade and subbase, which are not identical terms, and should not be mixed. Subgrade means the original layer of the ground, which needs to be properly compacted and developed for the proper smoothness. Subbase is the layer made on the compacted subgrade, according to the guideline of Dramix, which is cement-bonded layer or spread shingle/pebble layer. The previously mentioned modulus of subgrade reaction has to be checked on the subbase layer before beginning of pouring the concrete. Dramix suggests industrial floor constructed with subbase (so a floor poured directly to the subbase, without separation film), where the goal is not the prevention of cracks, but rather controlling the size of cracks, that is the development of many widely located cracks that cannot be seen by the naked eye. It defines a minimal slab thickness of $140 \mathrm{~mm}$. It pays a special reference to the significance of concrete technology, as well as to the importance cement and aggregate types, the $w / c$ ratio, the applicable admixtures and the consistency. Dramix suggests a high fibre dosage for jointless industrial floors, and supplementary traditional steel bar reinforcement for critical locations. Curing the floor, as well as applying the admixture compensating shrinkage on the partially hardened concrete is especially relevant, after its hardening, which must be followed by flooding the floor with water and keeping it covered by a film for 14 days. Based on the guideline final loading of the floor is achieved after six weeks. According to the regulation of Dramix, even a 45-meter distance of construction joints can be reached by the proper concrete technology, designing, construction and curing.

Application of post tensioned reinforced concrete industrial floors is common in the United States, but currently there is no acceptable guideline for designing jointless industrial floors.

\subsection{Fibre Reinforced Concretes}

Although fibre reinforced concretes have been used for a long time in the industry, there are only a few designing methods available. Among these TR34 is the most popular for industrial floors. While the third edition uses the $R_{\mathrm{e} 3}$ value for characterizing fibre reinforced concretes, then the fourth edition tended to use solely the more precise CMOD value (Crack Mouth Opening Displacement) of residual flexural tension strength. The $R_{\mathrm{e} 3}$ value can be obtained by a laboratory test defined by the Japanese JSCE [6] standard, while the CMOD value of residual flexural tension strength can be obtained by the analysis defined in the RILEM TC162 [7] standard. The values of residual flexural tension strength characterize fibre reinforcement more accurately than the value of $R_{\mathrm{e} 3}$. The guideline clearly states that only the steel- or macro-synthetic fibres can be used during designing, micro fibres (mono and fibrillated) cannot be considered from a static aspect, similarly like British-Adopted European Standard BS EN 14889-2 [8]. Micro fibre reinforced concrete as a concrete structure can be designed with a linear calculation. Based on this "replacing the reinforcement by micro fibres" cannot be valid from a structural aspect.

ACI and TR34 2003 take the data of the fibre reinforced concrete according to the Japanese standard [6], the TR34 2013 does so according to the RILEM TC162 [7] standard, while the Austrian guideline does so according to the Richtlinie Faserbeton guideline [9]. Material parameters of the steel- or macro synthetic fibre reinforced concrete should be provided by the 
manufacturer based on his own examinations, but for larger projects it is worth taking the results deriving from laboratory analysis of test specimens made from the concrete planned to apply for the project. As the examination of the concrete should be carried out at 28 days of age, it rarely gets completed before the project.

\subsection{Linear and Non-linear Design}

Industrial floor, from a static aspect, is a slab structure flexibly supported on its whole surface by linear or non-linear springs, its material model can be approached by a linear material model until its crack-free state, and for reinforced or fibre reinforced concrete a linearly elastic-plastic material model can be used on the tension side, subject to certain restrictions. Based on the above, concrete- or micro fibre reinforced (mono or fibrillated) concrete industrial floors can be approached by an elastic material model, while reinforced- or macro fibre reinforced concrete industrial floors by a linearly elastic-plastic material model. So a linear spring can be used to calculate upon considering the support, which cannot handle rising of the industrial floor, or with a non-linear spring, which does not work upon tension, so the floor can rise. So the naming non-linear design can refer to the supports or the material model being non-linear. While the former can be managed by most of the software, then the latter can be calculated by complex finite element software only. Only crack-free concrete can be designed in case of a linear material model, which has a basic condition of the constructed industrial floor not cracking under the hardening of the concrete. This can be achieved by the proper concrete technology (small shrinking concrete, applying micro fibres) and by the proper method of curing lasting for a proper amount of time. Achieving this requires a complex designing knowledge and experience, and as from an engineering aspect, there is not any reserve in a structure such as this one.

\section{Summary}

There are numerous guidelines for designing industrial floors, and all have their benefits and disadvantages. Generally these guidelines are not applied by the engineers; they deflect designing and responsibility to the manufacturers. In this publication the most significant industrial floor guidelines were presented, examining their benefits and disadvantages, as well as the significant designing issues recognized upon designing industrial floors. Although industrial floors are only a small part of the total building, they have a significant role due to the constantly growing levels of demand, which require engineering design. The next part of our series will feature an exact design method.

\section{References}

[1] ACI. 2010. 360.R-10 Guide to Design of Slabs-on-Ground. p. 76.

[2] Advisory Committee on Technical Recommendations for Construction. 2006. CNR-DT 204/2006 Guide for the Design and Construction of Fiber-Reinforced Concrete Structures. Rome.

[3] Concrete Society. 2003. TR34 Concrete Industrial Ground Floors. Crowthorne.

[4] Lohmeyer, G., and Ebeling, K. 2008. Betonpadlók gyártó-és raktárcsarnokban. Budapest: Publikál Kft.

[5] European Committee for Standardization. 2004. EUROCODE EN. 1992: European Code for Design of Concrete Structures. Brussels.

[6] Japan Society of Civil Engineers. 1985. Method of Tests for Flexural Strength and Flexural Toughness of SFRC, Standard JSCE SF-4.

[7] Vandewalle, L., et al. 2000. "RILEM TC 162-TDF: Test and Design Methods for Steel Fibre Reinforced Concrete." Materials and Structures 33 (2002): 3-5.

[8] British-Adopted European Standard. 2006. Fibres for Concrete: Polymer Fibres-Definitions, Specifications and Conformity, Standard BS EN 14889-2.

[9] Österreichische Vereinigung für Beton-und Bautechnik. 2008. Richtlinie Faserbeton. Wien. 